\title{
11 Shaping gendered responses to climate change in South Asia
}

\author{
Asha Hans, Anjal Prakash, Nitya Rao, and \\ Amrita Patel
}

\section{Introduction}

The purpose of Engendering Climate Change: Learning from South Asia, as explained in the introduction to the volume, was to explore and contribute to the climate discourse. Climate change is a historically shifting conversation and the knowledge which emerged in this volume is specific to the gendered understanding of the climate change hotspot study sites of South Asia. In this area, the vulnerabilities created by climate change have been challenged by women and men, sometimes successfully, and at other times, as observed in these writings, with an increase in vulnerabilities. Globally and in South Asia, policies have reflected the intention of meeting climate targets, yet the conversations on climate change have not been gendered. In recent years the situation has begun to improve as a debate with a gendered underpinning is being built globally and in South Asia to understand the vulnerabilities faced by women (Rao et al. 2019; Fernandes 2018; Ngigi et al. 2017; Goh 2012; Ahmed and Fajber 2009).

\section{An evolving gendered framework for climate change research}

Three key insights emerge from our discourse. The first is the importance of attention to inter- and intra-household relations in research. The analysis in the various chapters is based on lived experiences of women who are vulnerable to climate change. It reveals how their roles change within and outside the household in terms of relationships and structures. Within this framework we see how the household responds to risk and adapts to the stresses created by climate change. Second, this research establishes an improved understanding of the gendered impacts of climate change and risk management through adaptive strategies undertaken by local communities. Third, we explore how vulnerabilities are gendered, and agency is constructed, despite the existence of social and political barriers across the states of South Asia.

Based on these arguments, the analytical framework assumes that alternate future pathways require gendered policy responses. These need to include the costs of adaptation efforts and strategies through increased 
financial allocations and research on issues critical to gender equality and climate justice in South Asia.

\section{Power across geographical locations: inter- and intra-household relations}

The writings in this volume provide a gendered conceptual lens on changes taking place within the household in the South Asian region. What emerges from the research enquiry is grounded on the assertion that "climate policy is not a grand global narrative, but rather a series of small-scale decisions made at various scales that affect individuals in disparate ways" (Bee et al. 2015:6). This insight gives an understanding of how the gendered social positions and power dynamics within the household intersect with geographical and climate variabilities. The research highlights the contexts and correlations in intra- and inter-household structures and gendered strategies adopted to manage risk. Intra-household choices have depended not only on the structure and composition but also the socio-cultural positioning of women and men within the household.

A basic highlight has been the recognition of gender diversity within the household, that it varies by age, ethnicity, economic class and geographical location. Across the various chapters, evidence is presented on changing gender roles and the sharing of labour and assets. To obtain this evidence authors have engaged with households through the use of different methodologies, but they all take a critical lens that goes beyond the binary understandings of gender (Singh, participatory and Hazra, Vincent, quantitative survey). These investigations, which have been related to how gender is inscribed in the household, explore its multi-faceted dimensions and the diverse ways in which intersectionality is constructed and enacted in practice.

In this context we can use Seager's argument that globally, climate change has to be viewed from a perspective of "privilege, power and geography" (Seager and Olson 1986). From a feminist lens too, privilege and power are two important constituents of patriarchy which exist across South Asia (White 2017; Chowbey 2017; Sultana 2012; Isran and Isran 2012; Kabeer 1997; Kandiyoti 1988). This is a significant dimension, as we have discovered that while women exercise individual agency in responding to climate change, their reactions are located within socio-cultural contexts of patriarchy.

Despite the historical resistance to women's exclusion and abuse, patriarchy has not found a place in climate change research even when the issues are feminized. This is because of, as Enloe argues, "a lack of feminist curiosity" (Enloe 2017: 164). It is by increasing our curiosity about the household in climate hotspots, increasing our understanding and acting on it, that we can dismantle it. Gilligan and Snider argue that this is imperative as it is "powerful in shaping how we can see the world, that it can literally keep us from seeing what is right" (2018: 38). This script is familiar as it exposes 
the history of gendered relations in their narrow template that does not demonstrate interconnectedness outside the binaries.

The shifting dynamics of this gendered binary can be observed in the changed roles: it was found that men who do not migrate do share household burdens, for example, fetching water, perceived as women's work, and that women assume new gendered roles in agriculture (Solomon and Rao, this volume). Limiting ourselves to a binary enquiry would, as what Gilligan and Snider have suggested, lose sight of the multi-dimensional identities of women as mothers, workers, displaced or migrants, thus overlooking their differential roles. Findings across the chapters reveal that women's vulnerability and agency is shaped in inter-household and intra-household contexts, and related to their ability to access material assets and markets, work and develop adaptive strategies seeking to diversify their livelihoods. Some of the chapters demonstrate that households headed by women, including widows, have made inroads into the male locations of power.

Caste plays an important role in households, and Scheduled Caste women in India tend to be highly vulnerable in terms of access to water, for instance. Yet they do emerge with enhanced power when equipped with livelihood diversification skills (Rijhwani in this volume). Widows, as expected, are highly vulnerable but do overcome some adversities with the support of NGOs and the government, leaving non-widows relatively poorer and with higher workloads and responsibilities (Hazra et al. in this volume). This differentiation is again highlighted when older women with higher involvement in household decision-making are still not found to be the final decision makers, as men still dominate crucial adaptation decisions, especially those related to agriculture. This is not only a result of a patriarchal culture of control over assets and resources by men but of patriarchal government policies that target only men for agriculture training and extension programmes (Qaisrani and Batool in this volume).

Gendered migration research reveals that the male-female binary in the household intersects with those of labour markets (Singh 2019; Chant 1998; Lawson 1998). Significantly in this context, patriarchy emerges in restricting women's rights to migrate; for instance in Pakistan, women's mobility was observed to be restricted to avoid negative gossip about them, and when husbands are away young newly married women face further restrictions (Qaisrani and Batool in this volume). In both migrant and non-migrant locations, women's work is increasing, as work at home is combined with newer livelihoods ranging from animal husbandry to mill work. There are other critical issues such as the loss of women's agency when their personal assets, such as gold, are taken by husbands to pay for digging borewells (Solomon and Rao in this volume).

A contextual analysis, as we attempt in this book, contributes to a broader understanding of vulnerability derived from social discrimination and political inaction, while also pointing to the small but significant ways in which women are negotiating unequal power relations. Gendered changes due to 
the changing climate go beyond the binary understanding of gender and are inclusive of caste, class and ethnic diversity. Women from wealthier families, for instance, do not work in agriculture, though they might still be responsible for domestic water collection. The chapters draw attention to the often invisible role of intra-household decisions in enhancing vulnerabilities, and to attempts by women to break patriarchal barriers by evolving new gendered roles or engaging with collective action. This helps us to understand the relationships between the drivers of patriarchy and climate change, whether it is in the selling of gold to buy a water source or restrictions on women's mobility.

Future research needs to further amplify this situation to enable a better understanding of patriarchal control over decision-making, while at the same time uncovering changes in men's roles where these are taking place. Women within households are contributing to the creation of new approaches and techniques to meet the challenges posed by climate change, and this needs to be recognized both in research and policy.

\section{Communities and gendered impact of climate change: risk management through adaptive strategies}

Tracing common gendered trends across countries and gendered strategies adopted across borders has provided critical knowledge of gendered transformation at the community level. In the four countries in this volume, women's contribution to the development of climate resilience can be seen in their robust response to the adverse impacts of climate change.

Specific strategies for each type of hazard are required in South Asia, as there are storm surges, cyclones, flooding, drought, sea-level rise, melting snow and landslides, as witnessed in the chapters in this volume. These changes traverse semi-arid zones, mountainous and delta regions. Heat has emerged as in important issue with which women have to cope, reducing their work output and creating health issues (Abbasi et al. in this volume). The learnings from various authors exploring gendered responses to climate change are reflected in their attempts to shift patterns of behaviour. The scholarship is well defined, for instance as a consequence of climate change women's involvement in agriculture changes, often increasing, with women taking on additional roles as their men migrate in search of other work. Yet given their limited ownership of land, productivity and yields remain relatively low, particularly in contexts of climate change and food insecurity (Goodrich et al. 2019; Rao et al. 2020). With declining agricultural yields, women cope by shifting to cash crops, crop diversification and the adoption of climate-resilient crops, all of which boost their purchasing power and food security. However, it is usually men who remain the decision makers and carry out technology-related work. By relegating cash crops as an enterprise under men's purview, society restricts women's role in decision-making, while increasing demands on their time (Solomon, Rao in this volume). 
One of the major contributions of the volume is the study of climate change related to water availability and differentiated water use practices in India that are impacting men and women within the household as well as the community. Water in South Asia has been a communal property (Mangi et al. 2019; Akter et al. 2017; Price et al. 2014). Its usage shows a shift from communal to individual control where purchasing power defines the gendered positioning, with women having less purchasing power. These impacts are differentiated across levels with shifts in work burdens within households, the erosion of traditional institutions at community level, and over-extraction and growing reliance on private water at a watershed level. For example, people with borewells can access water for irrigation and those with purchasing power can buy drinking water from tankers. Water shortages therefore have equity implications as they disadvantage the most marginalized and exacerbate existing vulnerabilities (Singh in this volume). Within households, women have to negotiate for the use of water, usually losing out, as men access it for irrigation, while women need it for maintaining livestock. Scheduled Caste women speak of appropriation of tanker water by upper-caste households and this finding accords with the increase in public water conflicts across India. We are increasingly becoming aware that when water shortages increase in climate-change situations, conflict over water will also increase (Mangi et al. 2019). Future research needs to both define and analyze the gendered impact of water conflict in climate-change situations. At the same time these conflicts are placing emphasis on new actors, such as middlemen who take advantage of these shortages, and this is an indicator of change linked to climate to which due attention must be paid by policy makers and researchers. The emergence of a private, informal water delivery sector undermines local sustainability and tends to exclude women-headed households. To face the challenge, a knowledge-based climate adaptation strategy can build women's capacity and contribute to their knowledge.

Work on migration and climate change has been increasing, with migration visualized as a distress response to climate change across the hotspots. Usually young men move out in search of livelihoods as they have to cope with crop failures, deteriorating pastures and increasing poverty. This results in an increase in women-headed households. Migration across South Asia is seen as a positive strategy (Adger et al. 2015; Afifi et al. 2016; Gemenne and Blocher 2017), with different patterns of short-term, seasonal and more longer-term migration dominated by economic drivers (Abbasi in this volume), yet it has gendered outcomes.

Household dynamics change "tangibly and intangibly" when men migrate (Hosegood et al. 2007; Nguyen and Locke 2014), as this leaves women behind as the sole carers and workers in the household. Women adapt by taking on male responsibilities in their absence. There is no indication whether workload benefits in the household are shared equally. Remittances from migrants do make a difference to the household, helping with poverty reduction and food security, as most remittances are spent on food 
(Szabo et al. 2018). This is especially the case when migrants cross borders and send back foreign exchange, for example, in Bangladesh and India (Mahanadi Delta) (Vincent and Hazra in this volume).

Male migration needs more research, as vulnerability may not be confined to women, but also affects the men and the community. Migrating men face health issues as there is no health cover available when they work in the unorganized sector or face problems due to hazardous work (Udas et al. in this volume). Thus, climate change-linked migration requires new policy initiatives which are gendered and take into account the vulnerability of all groups.

While women have been adopting cash crops, hybrid seeds or mechanization (Qaisrani and Batool in this volume), seeking to build new skills for survival and strengthening livelihoods, they are often left out of technology change, or indeed finances to meet the new challenges. These inputs are usually identified as male needs and used as justifications for keeping women out of the fields of science, technology, engineering and maths (STEM) (Schmuck 2017). Women's work continues to be recognized as only within the household, even if they head households and engage with markets. Climate change and variability affect women-headed households more than others as their access to resources and knowledge is limited. Gendered vulnerabilities are thus determined by local factors such as exclusion from the market and technological interventions, together with the social structures of the household, the community and the state. Capacity building and improved finances become essential to their survival.

In analyzing the above issues, the authors have highlighted differentiated caste and class structures, and the implications for resource distribution and hence for policy and research (Udas et al. in this volume). It can be argued that adaptation policies and programmes that are responsive to community needs, seek to create an equal playing field. If this does not happen, then climate responses end up widening gender gaps. Across the hotspots, there can be no single response or solution to the impacts of climate change, as gendered distinctions are part of the varied factors in household-community interplay. While women may exercise individual agency, this does not necessarily remove the social vulnerability to which they are subject.

\section{Expanding the fiscal and governance framework in South Asia}

There is limited research on engendering climate change in South Asia (Bhatta et al. 2015; Rao et al. 2019). Recognizing vulnerability as a first step has been taken by all four countries in their climate change policies, but they have failed to go beyond this, as can be seen from the four countries' Nationally Determined Contributions to the UNFCC (WEDO 2016). The South Asia Association of Regional Countries (SAARC), which includes all the four countries in this volume, has a structure linked to climate change which started with the establishment of the SAARC Disaster Management Centre (SDMC) in 2006. Climate-related security risks above and beyond 
natural disasters were broadly emphasized in the 2007 Declaration of the 14th SAARC Summit. Though regional levels form the basis for the international and local, in South Asia, progress on cross-country policies has not been possible. Despite the several institutions that have been established by SAARC, they have not been able to produce concrete results and especially any gendered response or finance (Krampe and Swain 2018). The South Asian scholarship in the volume is vibrantly focused on the way gender is constructed as well as contested. All chapters, whether on India, Bangladesh, Pakistan or Nepal, address gender concerns in contexts of climate change and represent an important direction for the future. Women in South Asia carry out work within the home and in agriculture, are the main carers for the family, and in climate change situations also take on work that was traditionally done by men. By recognizing only the vulnerability of women and overlooking their agency, national policies are contributing to perpetuating a stereotypical image of defenceless women. Thus their capacity to mitigate the impacts of climate change is overlooked.

Though finance for climate change is part of the political debate at the international level, the targeted inclusion of women has yet to be initiated in South Asia. Policies on financial support for those who are affected and face survival issues requires budgets specifically designated for the gendering of climate change in the development economy. There is a need for increased income, grants, technology transfers and other forms of financial support which would require decisions at international and national level.

Some of the work carried out by women, such as crop rotation, crop substitution and shifting timings should be, but are not, part of any climate change funding (Williams 2016). Lack of finance may therefore have implications, as observed in the case of the drying up of borewells and women's assets, including gold, being spent on more borewells in the absence of cash. This disproportionately affects the Scheduled Castes and Tribes and poor households (Solomon and Rao in this volume).

\section{Building capacities for gendered research in climate change: unpacking methodology and epistemology}

Climate change linked to a new transformative agenda grounded in gendered concepts of equality requires research at each stage of systems change. However, systems vary in each country, hence the determinants of adaptive capacity also function differently in different contexts (Smit and Wandel 2006: 288; Moosa and Tuana 2014).

There is a need to build the capacities of researchers for designing, collecting and analyzing sex-disaggregated data related specifically to social processes and adaptive demands. Disaggregation, however, is not enough; deeper analyses of gender identities, power differentials, social relations and change are also required. For the future, studies must address the lack of a robust methodology to address gender inequalities from a multi-disciplinary perspective in a context of climate change. A distinguishing characteristic 
of this methodology has to be that it is an active engagement with women and men but must go beyond binaries and include identities of class, caste, community, and in the South Asian context, minorities. It should be able to explore missing as well as contextually situated research requirements of a 'socially engaged research' that interrogates existing knowledge while producing new knowledge based on ethical responsibility and making the reader aware of exclusion. With this in mind, through this volume we have used a diversity of methods ranging from participatory to qualitative and quantitative research to provide complex understandings, as authors have explored the interface between women and men across different social groups and positions, and climate change. Common to the research has been the use of critical methods to unpack a range of intersectionalities at work in women's everyday lives.

The epistemological position of women in climate change research needs to be based on women's lived experiences. This will enable future gendered research to view women and men through a critical socio-political lens. It will enable research and policy makers to go beyond the vulnerability paradigm and patriarchal structures to those that are inclusive of women's agency. An understanding of household dynamics shows women changing gender norms to control resources and remove cultural barriers. A challenging critique is thus making both women's and men's social worlds visible through the epistemic values of experiences.

There is a missing link between research and policy, and this empirical data could inform policy and development professionals to implement interventions that are gendered. Building climate resilience for both women and men cannot just be driven by mainstreaming gender in climate change policy; it requires women's needs and requirements to be integrated into all the other national and local policies and actions that shape and construct discriminatory gender roles in society and within households.

\section{References}

Adger, W., Arnell, N., Black, R., Dercon, S., Geddes, A., and Thomas, D. 2015. 'Focus on Environmental Risks and Migration: Causes and Consequences.' Environmental Research Letters, 10(6).

Afifi, T., Milan, A., Etzold, B., Schraven, B., Schulz Rademacher, C., Sakdapolrak, P., and Warner, K. 2016. 'Human Mobility in Response to Rainfall Variability: Opportunities for Migration a Successful Adaptation Strategy in Eight Case Studies.' Migration and Development, 5: 254-274.

Ahmed,S., andFajber,E.2009.'EngenderingAdaptation to ClimeVariability in Gujarat. India.' Gender and Development, 17: 33-50. doi:10.1080/13552070802696896

Akter, S., Rutsaert, P., Luis, J., Htwe, N.M., Raharjo, S.B., and Pustika, A. 2017. 'Women's Empowerment and Gender Equity in Agriculture: A Different Perspective from Southeast Asia.' Food Policy, 69: 270-279. doi:10.1016/j. foodpol.2017.05.003.

Bee, B.A., Rice, J., and Trauger, A. 2015. 'A Feminist Approach to Climate Change Governance: Everyday and Intimate politics.' Geography Compass, 96): 339-350. 


\section{Asha Hans, Anjal Prakash, Nitya Rao, and Amrita Patel}

Bhatta, G.D., Aggarwal, P.K., Poudel, S., and Belgrave, D.A. 2015. 'Climate-induced Migration in South Asia: Migration Decisions and the Gender Dimensions of Adverse Climatic Events.' Journal of Rural and Community Development, 10: 1-23.

Chant, S. 1998. 'Households, Gender, and Rural-urban Migration: Reflections on Linkages and Considerations for Policy.' Environment and Urbanization, 10(1): 5-21.

Chowbey, P. 2017. 'Women's Narratives of Economic Abuse and Financial Strategies in Britain and South Asia.' Psychology of Violence, 7: 459-468.

Enloe, C. 2017. The Big Push: Exposing and Challenging the Persistence of Patriarchy. Oxford: Myriad Editions.

Fernandes, L., (ed.). 2018. Routledge Handbook of Gender in South Asia. London: Routledge.

Gemenne, F., and Blocher, J. 2017. 'How Can Migration Serve Adaptation to Climate Change? Challenges to Fleshing Out a Policy Deal.' Geographical Journal, 183: 336-347.

Gilligan, C., and Snider, N. 2018. Why Does Patriarchy Persist? Cambridge, UK: Polity Press.

Goh, A.H.X. 2012. 'A Literature Review of the Gender Differentiated Impacts of Climate Change on Women's and Men's Assets and Well Being in Developing Countries.' CAPRi Working Paper No. 106. Washington, DC: International Food Policy Research Institute.

Goodrich, C.G., Udas, P.B., and Larrington-Spencer, H. 2019. 'Conceptualizing gendered vulnerability to climate change in the Hindu Kush Himalaya: Contextual conditions and drivers of change', Environmental Development, 31: 9-18. doi:10.1016/j.envdev.2018.11.003.

Hosegood, V., Preston-Whyte, E., Busza, J., Moitse, S., and Timaeus, I.M. 2007. 'Revealing the Full Extent of Households' Experiences of HIV and AIDS in Rural South Africa.' Social Science \& Medicine, 65: 1249-1259.

Isran, S., and Isran, A.M. 2012. 'Patriarchy and Women in Pakistan: A Critical Analysis, Interdisciplinary.' Journal of Contemporary Research in Business, 4(6): 835-859.

Kabeer, N. 1997. 'Women, Wages and Intra-household Power Relations in Urban Bangladesh.' Development and Change, 28: 261-302.

Kandiyoti, D. 1988. 'Bargaining with Patriarchy.' Gender \& Society, 2: 274-290.

Krampe, F., and Swain, A. 2018. 'Is SAARC prepared to combat climate change and its security risks?'. The Third Pole Net. https://www.thethirdpole.net/en/2018/09/06/ is-saarc-prepared-to-combat-climate-change-and-its-security-risks/.

Lawson, V. 1998. 'Hierarchical Households and Gendered Migration: A Research Agenda.' Progress in Human Geography, 22(1): 32-53.

Mangi, F., Kay, C., Chaudhary, A. 2019. 'A Water Crisis Is Brewing Between South Asia's Arch-Rivals.' Bloomberg. https:/www.bloomberg.com/news/ features/2019-01-25/a-water-crisis-is-brewing-between-south-asia-s-arch-rivals.

Moosa, C.S., and Tuana, N. 2014. 'Mapping a Research Agenda Concerning Gender and Climate Change.' Sociological Review, 57: 124-140.

Ngigi, M., Mueller, U., Birner, R. 2017. 'Gender Differences in Climate Change Adaptation Strategies and Participation in Group Based Approaches: an Intrahousehold Analysis from Kenya.' Ecological Economics, 138: 99-108.

Nguyen, M.T., and Locke, C. 2014. 'Rural-urban migration in Vietnam and China: Gendered Householding, Production of Space and the State.' Journal of Peasant Studies, 41: 855-876. 
Price, G., Alam, R., Hasan, S., Humayu, F., Kabir, M.H., Karki, C.S., Mittra, S., Saad, T., Saleem, M., Saran, S., Shakya, P.R., Snow, C., and Tuladhar, S. 2014. Attitudes to Water in South Asia. London: Chatham House Report.

Rao, N., Lawson, E.T., Raditloaneng, W.N., Solomon, D. and Angula, M.N. 2019. 'Gendered Vulnerabilities to Climate Change: Insights from the Semi-arid Regions of Africa and Asia.' Climate and Development, 11(1): 14-26. doi:10.1080/1756 5529.2017.1372266.

Rao, N., Singh, C., Solomon, D., Camfield, L., Sidiki, R., Angula, M., Poonacha, P., Sidibé, A., and Lawson, E. T. 2020. 'Managing risk, changing aspirations and household dynamics: Implications for wellbeing and adaptation in semi-arid Africa and India.' World Development, 125, 104667.

Schmuck, C. 2017. Women in STEM Disciplines: The Y factor. 2016 Global Report on Gender in Science, Technology, Engineering and Mathematics. Springer International Publishing Switzerland.

Seager, J., and Olson, A. 1986. Women in the World: An International Atlas. New York: Simon and Schuster.

Singh, C. 2019. 'Migration as a driver of changing household structures: implications for local livelihoods and adaptation.' Migration and Development, 8(3): 301-319. doi:10.1080/21632324.2019.1589073.

Smit, B., and Wandel, J. 2006. 'Adaptation, Adaptive Capacity and Vulnerability.' Global Environmental Change, 16(3): 282-292. doi:10.1016/j. gloenvcha.2006.03.008

Sultana, A. 2012. 'Patriarchy and Women's Subordination: A Theoretical Analysis.' The Arts Faculty Journal, 4(1): 1-18.

Szabo, S., Adger, W.N., and Matthews, Z. 2018. 'Home is Where the Money Goes: Migration Related Urban Rural Integrations in Delta Regions.' Migration and Development, 2324: 1-17.

WEDO. 2016. 'Gender and Climate Change: Analyses of Intended Nationally Determined Contributions.' https://wedo.org/wp-content/uploads/2016/11/ WEDO_GenderINDCAnalysis-1.pdf.

White, S.C. 2017. 'Patriarchal Investments: Marriage, Dowry and the Political Economy of Development in Bangladesh.' Journal of Contemporary Asia, 47 (2): 247-272. doi:10.1080/00472336.2016.1239271.

Williams, M. 2016. Gender and Climate Change Financing: Coming Out of the Margin. London: Routledge. 